\title{
Coronary microvascular ischemia in hypertrophic cardiomyopathy - a pixel-wise quantitative cardiovascular magnetic resonance perfusion study
}

Tevfik F Ismail ${ }^{1,2+}$, Li-Yueh Hsu ${ }^{3+}$, Anders M Greve ${ }^{3}$, Carla Gonçalves ${ }^{1}$, Andrew Jabbour ${ }^{1}$, Ankur Gulati ${ }^{1}$, Benjamin Hewins ${ }^{1}$, Niraj Mistry ${ }^{1,2}$, Ricardo Wage ${ }^{1}$, Michael Roughton ${ }^{4}$, Pedro F Ferreira ${ }^{1,2}$, Peter Gatehouse ${ }^{1,2}$, David Firmin ${ }^{1,2}$, Rory O'Hanlon ${ }^{1}$, Dudley J Pennell ${ }^{1,2}$, Sanjay K Prasad ${ }^{1,2+}$ and Andrew E Arai ${ }^{3 *+}$

\begin{abstract}
Background: Microvascular dysfunction in HCM has been associated with adverse clinical outcomes. Advances in quantitative cardiovascular magnetic resonance (CMR) perfusion imaging now allow myocardial blood flow to be quantified at the pixel level. We applied these techniques to investigate the spectrum of microvascular dysfunction in hypertrophic cardiomyopathy (HCM) and to explore its relationship with fibrosis and wall thickness.

Methods: CMR perfusion imaging was undertaken during adenosine-induced hyperemia and again at rest in 35 patients together with late gadolinium enhancement (LGE) imaging. Myocardial blood flow (MBF) was quantified on a pixel-by-pixel basis from CMR perfusion images using a Fermi-constrained deconvolution algorithm. Regions-of-interest (ROI) in hypoperfused and hyperemic myocardium were identified from the MBF pixel maps. The myocardium was also divided into 16 AHA segments.

Results: Resting MBF was significantly higher in the endocardium than in the epicardium (mean \pm SD: $1.25 \pm$ $0.35 \mathrm{ml} / \mathrm{g} / \mathrm{min}$ versus $1.20 \pm 0.35 \mathrm{ml} / \mathrm{g} / \mathrm{min}, \mathrm{P}<0.001)$, a pattern that reversed with stress $(2.00 \pm 0.76 \mathrm{ml} / \mathrm{g} / \mathrm{min}$ versus $2.36 \pm 0.83 \mathrm{ml} / \mathrm{g} / \mathrm{min}, \mathrm{P}<0.001)$. ROI analysis revealed 11 (31\%) patients with stress MBF lower than resting values $(1.05 \pm 0.39 \mathrm{ml} / \mathrm{g} / \mathrm{min}$ versus $1.22 \pm 0.36 \mathrm{ml} / \mathrm{g} / \mathrm{min}, P=0.021)$. There was a significant negative association between hyperemic MBF and wall thickness ( $\beta=-0.047 \mathrm{ml} / \mathrm{g} / \mathrm{min}$ per $\mathrm{mm}, 95 \% \mathrm{Cl}:-0.057$ to $-0.038, \mathrm{P}<0.001)$ and a significantly lower probability of fibrosis in a segment with increasing hyperemic MBF (odds ratio per $\mathrm{ml} / \mathrm{g} / \mathrm{min}$ : $0.086,95 \%$ Cl: 0.078 to $0.095, P=0.003)$.
\end{abstract}

Conclusions: Pixel-wise quantitative CMR perfusion imaging identifies a subgroup of patients with HCM that have localised severe microvascular dysfunction which may give rise to myocardial ischemia.

Keywords: Hypertrophic cardiomyopathy, Perfusion, Cardiovascular magnetic resonance, Microvascular dysfunction, Sudden cardiac death

\footnotetext{
*Correspondence: araia@nih.gov

${ }^{\dagger}$ Equal contributors

${ }^{3}$ Advanced Cardiovascular Imaging Laboratory, National Heart, Lung, and

Blood Institute, National Institutes of Health, Bethesda, Maryland, USA

Full list of author information is available at the end of the article
}

\section{Biomed Central}

(c) 2014 Ismail et al.; licensee BioMed Central Ltd. This is an Open Access article distributed under the terms of the Creative Commons Attribution License (http://creativecommons.org/licenses/by/2.0), which permits unrestricted use, distribution, and reproduction in any medium, provided the original work is properly credited. The Creative Commons Public Domain Dedication waiver (http://creativecommons.org/publicdomain/zero/1.0/) applies to the data made available in this article, unless otherwise stated. 


\section{Background}

Hypertrophic cardiomyopathy is a common inherited heart muscle disease which can lead to premature sudden cardiac death (SCD) or to progressive heart failure in a subset of patients [1-3]. Coronary microvascular ischemia has been implicated in the pathogenesis of replacement fibrosis $[4,5]$, which in turn has been associated with adverse outcomes [6-13]. However, myocardial replacement fibrosis is characteristically found in the mid-wall [14], whereas perfusion abnormalities are thought to preferentially affect the endocardium [15]. Varnava et al. found a poor correspondence between the distribution of small vessel disease and fibrosis on post-mortem histology [16]. The precise relationship between fibrosis and myocardial ischemia therefore remains unresolved.

Cardiovascular magnetic resonance (CMR) allows the non-invasive assessment of myocardial blood flow and replacement fibrosis without the use of ionising radiation [17]. Only one study to date has utilised multi-parametric CMR to quantitatively evaluate the relationship between perfusion abnormalities, left ventricular (LV) wall thickness, and fibrosis [18]. In keeping with previous studies that used positron emission tomography (PET) for the absolute quantification of myocardial blood flow (MBF), this study assessed perfusion using a sector-based approach [19-22]. This strategy creates territories that are of relevance for assessing epicardial coronary disease but which are arbitrary from a microcirculatory perspective. The use of a sector-based or global approach alone whilst improving signal-to-noise, may mask or significantly underestimate the local severity of perfusion defects due to coronary microvascular dysfunction [23]. This is of particular importance as the burden and severity of ischemia may be of prognostic importance as a mechanism leading to myocardial fibrosis, and independently as a trigger for ventricular arrhythmia $[19,24]$.

We have previously shown that first-pass gadoliniumenhanced CMR stress perfusion imaging allows the pixel-wise quantification of absolute MBF with high fidelity and spatial resolution [23]. We applied these pixel-level techniques to explore the severity of perfusion abnormalities in HCM and to assess their relationship to fibrosis and local wall thickness.

\section{Methods}

\section{Study population}

Thirty-six patients with HCM referred for CMR at the Royal Brompton Hospital were studied. HCM was diagnosed in accordance with standard clinical guidelines [25]. Patients were excluded if they had: conditions associated with coronary microvascular dysfunction such as diabetes; significant epicardial coronary artery disease on angiography (defined as $>50 \%$ diameter stenosis in a major coronary artery); previous gradient reduction therapy; contraindications to CMR, adenosine, or gadolinium-based contrast agents. The study was approved by the National Research Ethics Service and was conducted in accordance with the principles set out in the declaration of Helsinki, with written informed consent obtained from all patients.

\section{Image acquisition}

All patients were asked to abstain from caffeine-containing beverages or drugs for 24 hours prior to imaging and from $\beta$-blockers and rate-limiting calcium channel antagonists for 48 hours prior to imaging. Images were acquired using a dedicated $1.5 \mathrm{~T}$ scanner with a twelvechannel phased-array receiver coil (Siemens Magnetom Avanto, Siemens AG Healthcare Sector, Erlangen, Germany). A retrospectively-gated balanced steady-state free-precession sequence was used to obtain breath-hold cine images in three long-axis planes, followed by a contiguous stack of short axis slices from the atrioventricular ring to the apex [26]. The end-systolic frames of the long-axis cine images were used to plan the acquisition of three short axis perfusion images to cover the base, mid-LV and the apex. Adenosine was infused at $140 \mathrm{mcg} / \mathrm{kg} / \mathrm{min}$ for a minimum of 4 minutes to achieve hyperemia. After measurement of heart rate and blood pressure at peak stress, gadolinium contrast (Gadovist, Bayer-Schering, Berlin, Germany, $0.1 \mathrm{mmol} / \mathrm{kg}$ ) was rapidly injected at $3.5 \mathrm{ml} / \mathrm{s}$, followed by $15 \mathrm{ml}$ saline at $7 \mathrm{ml} / \mathrm{s}$ using a power injector (Medrad UK, Ely, Cambridgeshire, UK) to ensure a compact bolus entered the heart. A saturation-recovery prepared dualsequence approach with center-out hybrid echoplanar imaging (EPI) [27] was used for perfusion imaging with the following typical sequence parameters: fat saturation pulse, composite $90^{\circ}$ saturation preparation pulse for each slice [28], $28^{\circ}$ readout pulse, saturation recovery time to central raw data acquisition $90 \mathrm{~ms}$, repetition time $5.1 \mathrm{~ms}$, echo time $1.1 \mathrm{~ms}$, echo train length 4, field of view $360 \times$ $288 \mathrm{~mm}$, base resolution $160 \times 160$, slice thickness $8 \mathrm{~mm}$. The center frequency of the scanner electronics was manually tuned to water in a $10 \times 10 \times 10 \mathrm{~cm}$ volume encompassing the LV to optimise both fat suppression and center-out hybrid-EPI image quality [29]. The arterial input function slice used low-resolution fast low-angle shot (FLASH) imaging with an adiabatic B1-insensitive rotation type 4 saturation pulse [30].

Three short axis images and an image at the basal slice of the arterial input function were acquired every cardiac cycle for a minimum of 50 cycles. Two initial proton density-weighted images were acquired prior to the arrival of contrast as part of perfusion imaging and were used for subsequent surface coil intensity correction. After $\sim 10 \mathrm{~min}$, late gadolinium enhancement (LGE) images were acquired with an inversion recovery-prepared segmented turbo FLASH sequence [31]. Inversion times 
were optimised to null normal myocardium with images repeated in two orthogonal phase-encoding directions to exclude artifact. After a minimum of 30 minutes, rest perfusion imaging was carried out at the same slice positions.

\section{Image analysis}

Ventricular volumes, function, mass, and ejection fraction were measured using a semi-automated thresholdbased technique (CMRtools, Cardiovascular Imaging Solutions, London). All volume and mass measurements were indexed to body surface area [32]. End-diastolic LV wall thickness was determined for each of the 17 American Heart Association (AHA) segments excluding the apex [33]. Late enhancement was dichotomously assessed for each segment by an expert reader blinded to the perfusion data and considered to be present if there was an area of high signal intensity on a background of adequately nulled myocardium present in two orthogonal phase-encoding directions [12].

\section{Perfusion analysis}

Absolute MBF was quantified pixel-wise at rest and at peak stress as outlined in Figure 1 and as previously described [23]. In brief, endocardial and epicardial borders of the LV myocardium were manually traced using Argus CMR software (Syngo, Siemens Healthcare, Erlangen, Germany) to define myocardial regions-of-interest (ROI). Custom image processing software developed in the Interactive Data Language (Exelis Visual Information Solutions, Boulder, Colorado, USA) was used to correct surface coil-intensity bias and motion artifacts for each image series to ensure frame-to-frame correspondence of pixels. MBF was then quantified pixel-wise using model-constrained deconvolution as previously validated [23].

To avoid potential underestimation of the severity of perfusion defects in a sector-wise analysis, ROI analysis was performed using the MBF pixel maps to compare hypoperfused areas and remote hyperemic areas at stress to corresponding areas at rest. Hypoperfused areas were defined as areas which visually appeared to have the worst perfusion on stress perfusion pixel maps. Based on the minimum myocardial perfusion reserve index (MPRI = stress $\mathrm{MBF} /$ rest $\mathrm{MBF}$ ) as measured from these ROI, the cohort was divided into two groups for further comparison: severe microvascular dysfunction (defined as minimum MPRI < 1.0) and non-severe groups (minimum MPRI $\geq 1.0$ ).

To assess the relationship between perfusion, wall thickness, and the presence of late enhancement, the myocardium was also divided into 16 segments according to the 17-segment AHA model, omitting the apex. Segments were further divided into endocardial and epicardial layers to assess for transmural perfusion gradients [33]. Perfusion in areas of LGE was also compared with that in remote areas free of enhancement.

\section{Statistical analysis}

Continuous variables are expressed as mean \pm standard deviation (SD) for normally distributed variables and as medians with interquartile ranges for non-parametric data. The Kolmogorov-Smirnov test was used together with histograms to assess the normality of continuous data. Differences between parametric continuous variables were assessed using Student's t-test, and for non-parametric data, the Mann-Whitney U-test. Categorical data are presented as frequencies and percentages. Differences between categorical variables were assessed using the $\chi^{2}$ and Fisher's exact tests as appropriate.

To take into account correlation of repeated measurements and clustering of data from ROI and sectors within slices and patients, the perfusion data was analysed using a multilevel linear mixed effects model with patients treated as a random intercept. The relationship between the presence of LGE and perfusion was assessed using binary logistic regression together with a mixed

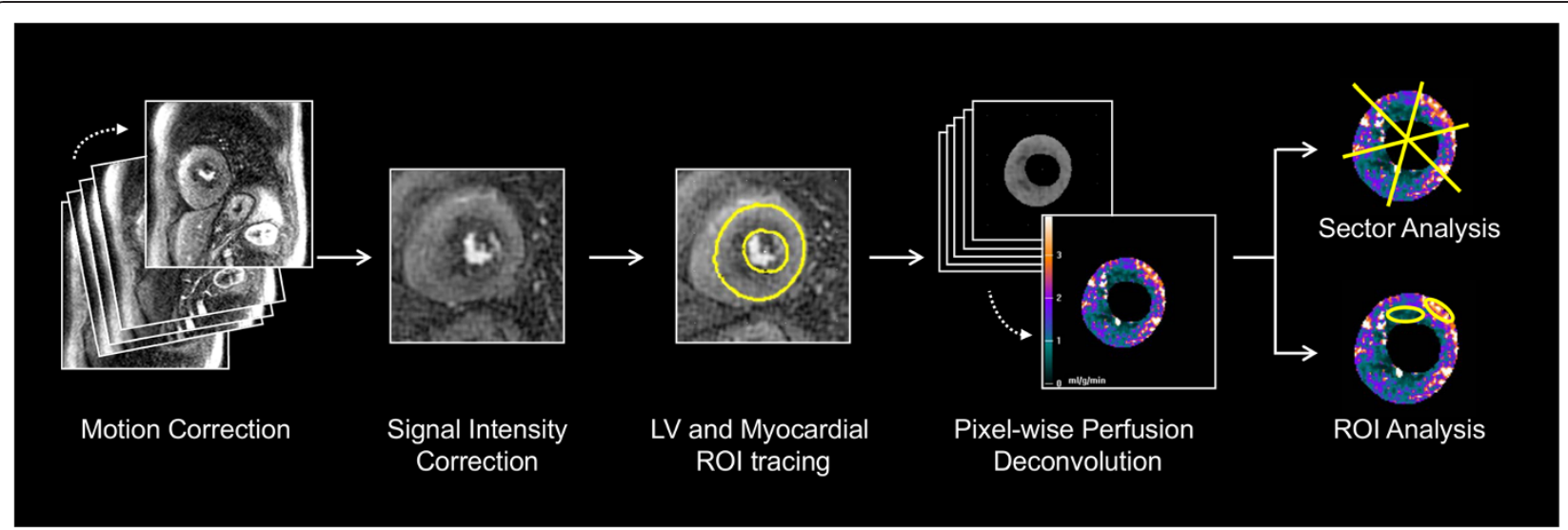

Figure 1 Summary of the steps involved in pixel-wise perfusion quantification and analysis. 
effects multilevel generalised linear model. Two-tailed values of $\mathrm{P}<0.05$ were considered significant. Statistical analysis was performed using Stata SE Version 12 (StataCorp, College Station, Texas, USA).

\section{Results}

\section{Study population}

The final study cohort was comprised of 35 patients (Table 1). One patient was excluded due to an inadequate vasodilator response to adenosine, which on further questioning was due to caffeine ingestion, leaving a final cohort of 35 patients. In response to adenosine, resting heart rate rose from a mean of $69.7 \pm 10.3$ to $92.6 \pm 13.6$ beats per minute with a small fall in mean arterial pressure from $94.8 \pm 11.7$ to $90.3 \pm 11.0 \mathrm{mmHg}$. Six out of 560 segments were excluded from analysis due to imaging artifact, encroachment of the left ventricular outflow tract on the basal slice, or problems with surface coil intensity normalisation. Overall, 99 segments had LGE.
Examples of perfusion pixel maps for the severe microvascular dysfunction and the non-severe patients are presented in Figure 2. Based on ROI analysis of the most significant perfusion defects seen in each patient, $11(31.4 \%)$ patients showed evidence of severe microvascular dysfunction. There were no significant differences between the severe and non-severe groups with respect to baseline clinical and demographic features, although there was a trend towards a higher incidence of left ventricular outflow tract obstruction amongst those with severe microvascular dysfunction (Table 1). However, with respect to the CMR findings, the maximum end-diastolic wall thickness was significantly higher in the severe microvascular dysfunction patients versus the non-severe patients (Table 2).

\section{Severity of perfusion abnormalities}

ROI analysis of hypoperfused areas in the severe microvascular dysfunction patients (Figure 3A) revealed that mean resting MBF was significantly lower in hypoperfused areas relative to remote areas from the same slices

Table 1 Baseline clinical and demographic characteristics of the study cohort stratified according to the presence/ absence of severe microvascular dysfunction

\begin{tabular}{|c|c|c|c|c|}
\hline & Non-severe & Severe & All patients & \\
\hline Characteristic - n (\%) & $24(68.6)$ & $11(31.4)$ & 35 & $P$ value \\
\hline Median age - years (IQR) & $58.9(52.3,67.5)$ & $52.0(42.5,63.6)$ & $57.1(48.5,66.6)$ & 0.256 \\
\hline Male sex - n (\%) & $18(75.0)$ & $7(63.6)$ & $25(71.4)$ & 0.490 \\
\hline Apical phenotype - n (\%) & $4(16.7)$ & $2(18.2)$ & $6(17.1)$ & 0.912 \\
\hline \multicolumn{5}{|l|}{ Risk factors for SCD } \\
\hline Sustained VTNF - n (\%) & $0(0)$ & $1(9.1)$ & $1(2.9)$ & 0.134 \\
\hline Family history of SCD - n (\%) & $2(8.3)$ & $1(9.1)$ & $3(8.6)$ & 0.941 \\
\hline Wall thickness $\geq 30$ mm - n (\%) & $1(4.2)$ & $1(9.1)$ & $2(5.7)$ & 0.560 \\
\hline Resting LVOT obstruction $\geq 30 \mathrm{mmHg}-\mathrm{n}(\%)$ & $1(4.2)$ & $3(27.3)$ & $4(11.4)$ & 0.046 \\
\hline Non-sustained VT - n (\%) & $3(12.5)$ & $0(0)$ & $3(8.6)$ & 0.220 \\
\hline Unexplained syncope - n (\%) & $3(12.5)$ & $1(9.1)$ & $4(11.4)$ & 0.769 \\
\hline \multicolumn{5}{|l|}{ Number of risk factors for SCD - n (\%) } \\
\hline 0 & $14(58.3)$ & $5(45.5)$ & $19(54.3)$ & \multirow[t]{3}{*}{0.296} \\
\hline 1 & $10(41.7)$ & $5(45.5)$ & $15(42.9)$ & \\
\hline $2+$ & $0(0.0)$ & $1(9.1)$ & $1(2.9)$ & \\
\hline \multicolumn{5}{|l|}{ NYHA functional class - n (\%) } \\
\hline I & $16(66.7)$ & $8(72.7)$ & $24(68.6)$ & \multirow[t]{4}{*}{0.720} \\
\hline$\|$ & $8(33.3)$ & $3(27.3)$ & $11(31.4)$ & \\
\hline III & $0(0)$ & $0(0)$ & $0(0)$ & \\
\hline IV & $0(0)$ & $0(0)$ & $0(0)$ & \\
\hline \multicolumn{5}{|l|}{ Medications at baseline $-\mathrm{n}(\%)$} \\
\hline$\beta$-blocker & $14(58.3)$ & $6(54.6)$ & $20(57.1)$ & 0.833 \\
\hline $\mathrm{Ca}^{2+}$-channel blocker & $0(0)$ & $1(9.1)$ & $1(2.9)$ & 0.134 \\
\hline
\end{tabular}

$\mathrm{QR}=$ Interquartile Range; $\mathrm{SCD}=$ Sudden Cardiac Death; VT = Ventricular Tachycardia; VF = Ventricular Fibrillation; LVOT = Left Ventricular Outflow Tract; NYHA = New York Heart Association. 


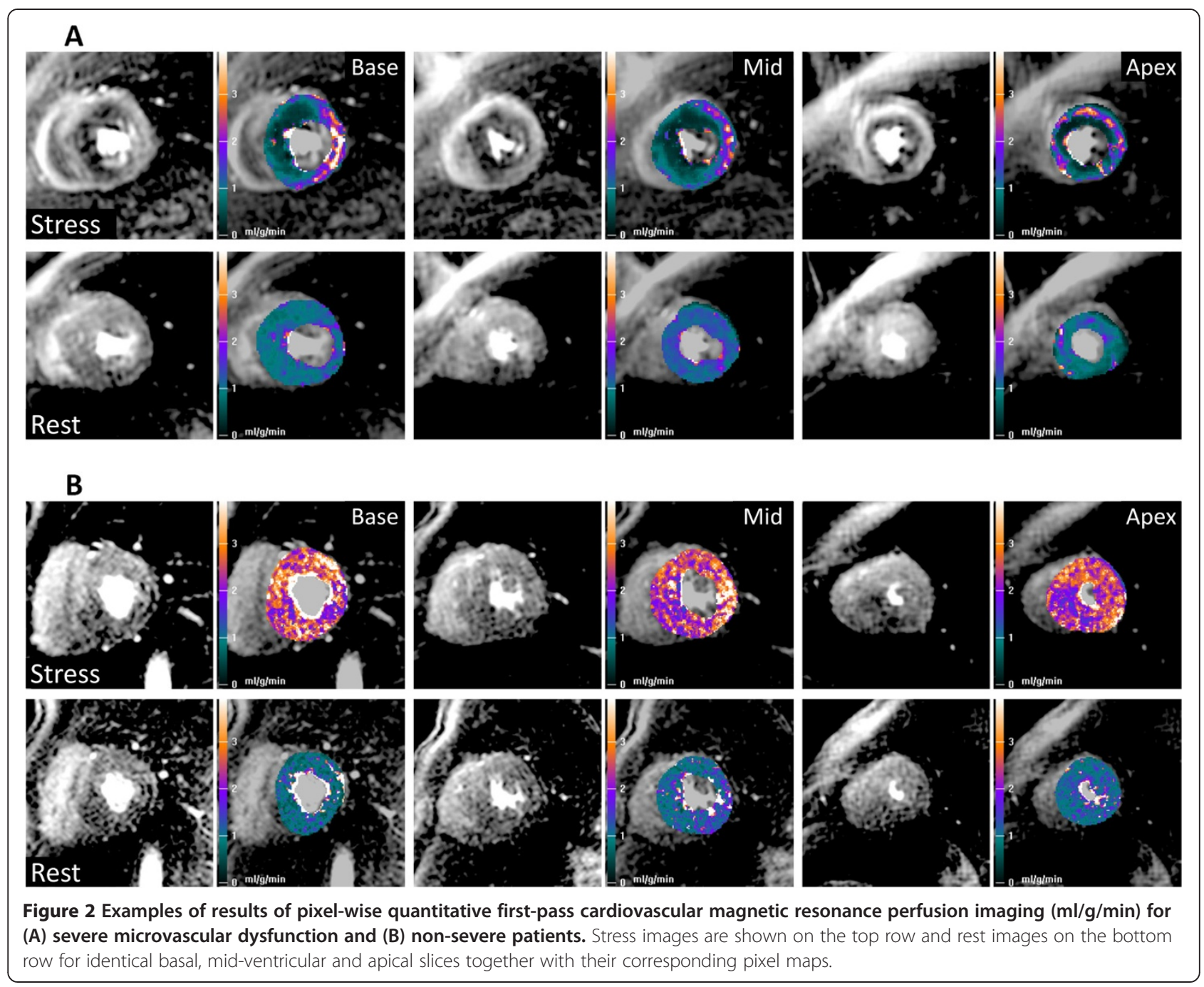

$(1.22 \pm 0.36 \mathrm{ml} / \mathrm{g} / \mathrm{min}$ versus $1.39 \pm 0.34 \mathrm{ml} / \mathrm{g} / \mathrm{min}, \mathrm{P}<$ $0.001)$. After stress, whereas MBF rose significantly in the remote areas $(1.39 \pm 0.34 \mathrm{ml} / \mathrm{g} / \mathrm{min}$ rising to $2.60 \pm$ $0.57 \mathrm{ml} / \mathrm{g} / \mathrm{min}, \mathrm{P}<0.001)$, stress $\mathrm{MBF}$ in hypoperfused ROI in patients with severe microvascular dysfunction not only failed to rise, but fell significantly from baseline values $(1.22 \pm 0.36 \mathrm{ml} / \mathrm{g} / \mathrm{min}$ falling to $1.05 \pm 0.39 \mathrm{ml} / \mathrm{g} /$ min, $\mathrm{P}=0.021)$. In contrast, for the non-severe patients
(Figure 3B), there was a significant rise in mean MBF with stress, even in the hypoperfused areas $(1.05 \pm 0.28 \mathrm{ml} / \mathrm{g} /$ $\min$ rising to $1.87 \pm 0.45 \mathrm{ml} / \mathrm{g} / \mathrm{min}, \mathrm{P}<0.001)$. ROI analysis in both groups showed significant hyperemic responses in regions remote from perfusion defects $(1.39 \pm$ $0.34 \mathrm{ml} / \mathrm{g} / \mathrm{min}$ rising to $2.60 \pm 0.57 \mathrm{ml} / \mathrm{g} / \mathrm{min}, \mathrm{P}<0.001$; and $1.20 \pm 0.31 \mathrm{ml} / \mathrm{g} / \mathrm{min}$ rising to $2.74 \pm 0.85 \mathrm{ml} / \mathrm{g} / \mathrm{min}$, $\mathrm{P}<0.001$, respectively). The ratio of the minimum MPRI

Table 2 Baseline cardiovascular magnetic resonance findings for the study cohort stratified according to the presence/ absence of severe microvascular dysfunction

\begin{tabular}{|c|c|c|c|c|}
\hline & Non-severe & Severe & All patients & \\
\hline CMR parameters - n (\%) & $24(68.6)$ & $11(31.4)$ & 35 & $P$ value \\
\hline Maximum end-diastolic wall thickness - mm & $18.9 \pm 4.5$ & $22.2 \pm 4.0$ & $19.9 \pm 4.6$ & 0.048 \\
\hline LV-EDV index $-\mathrm{ml} / \mathrm{m}^{2}$ & $68.5 \pm 15.1$ & $64.3 \pm 10.5$ & $67.2 \pm 13.8$ & 0.419 \\
\hline LV-ESV index $-\mathrm{ml} / \mathrm{m}^{2}$ & $19.5 \pm 7.9$ & $17.2 \pm 6.1$ & $18.8 \pm 7.4$ & 0.393 \\
\hline LV ejection fraction - \% & $72.0 \pm 8.3$ & $73.8 \pm 6.5$ & $72.5 \pm 7.7$ & 0.515 \\
\hline LV mass index $-\mathrm{g} / \mathrm{m}^{2}$ & $93.6 \pm 24.9$ & $103.4 \pm 30.0$ & $96.7 \pm 26.6$ & 0.318 \\
\hline
\end{tabular}

All values mean $\pm \mathrm{SD}$. CMR = Cardiovascular Magnetic Resonance; LV = Left Ventricular; EDV = End-diastolic volume; ESV = End-systolic volume. 


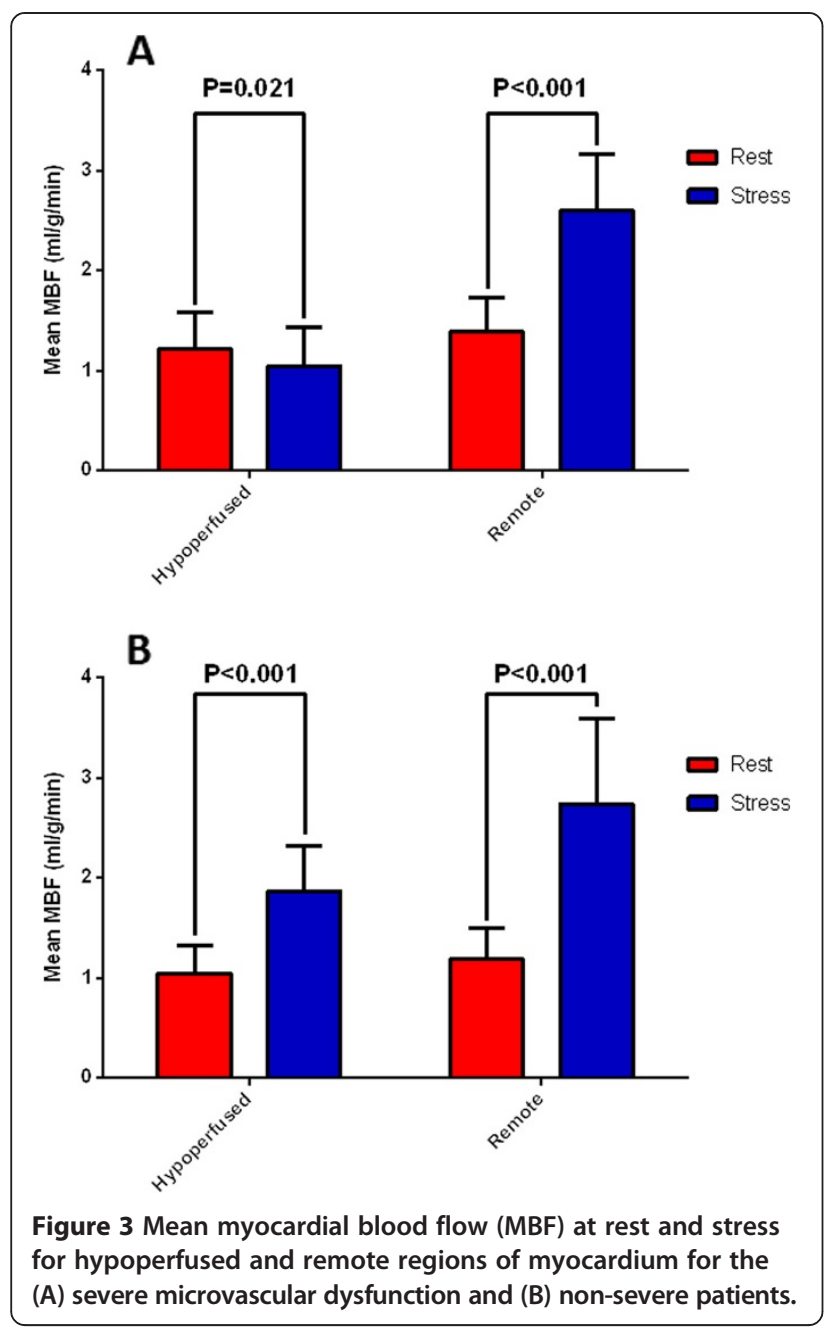

for hypoperfused areas to the maximum MPRI in remote regions was significantly lower in the severe microvascular dysfunction patients at $0.31 \pm 0.10$ versus $0.58 \pm 0.16$ in the non-severe group $(\mathrm{P}<0.001)$.

\section{Transmural distribution of blood flow in response to vasodilator stress}

Adenosine achieved hyperemia, with MBF rising significantly between rest and stress. When considering the most normal sectors in each of the patients, the mean MPRI was significantly lower in the severe versus non-severe patients for sectors as a whole and in endocardial subsectors, with a trend towards significance in the epicardium (Figure 4). When comparing the 16 segments in all the patients, MBF rose significantly with stress in whole sectors $(1.22 \pm 0.34 \mathrm{ml} / \mathrm{g} / \mathrm{min}$ rising to $2.22 \pm 0.76 \mathrm{ml} / \mathrm{g} /$ min, $\mathrm{P}<0.001)$ and in both endocardial and epicardial subsectors $(1.25 \pm 0.35 \mathrm{ml} / \mathrm{g} / \mathrm{min}$ rising to $2.00 \pm 0.76 \mathrm{ml} / \mathrm{g} /$ min, $\mathrm{P}<0.001$; and $1.20 \pm 0.35 \mathrm{ml} / \mathrm{g} / \mathrm{min}$ rising to $2.36 \pm$ $0.83 \mathrm{ml} / \mathrm{g} / \mathrm{min}, \mathrm{P}<0.001$, respectively). At rest, endocardial

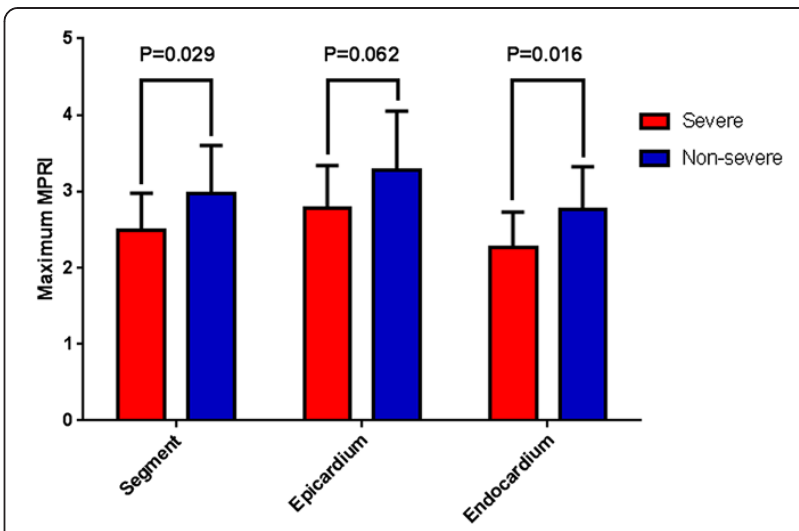

Figure 4 Myocardial perfusion reserve index (MPRI) in the severe and non-severe microvascular dysfunction groups for the most-hyperemic transmural segments, sub-epicardial, and sub-endocardial sub-sectors.

MBF was significantly higher than epicardial MBF (1.25 \pm $0.35 \mathrm{ml} / 100 \mathrm{~g} / \mathrm{min}$ versus $1.20 \pm 0.35 \mathrm{ml} / \mathrm{g} / \mathrm{min}, \mathrm{P}<0.001$ ) with an endocardial to epicardial MBF ratio of $1.05 \pm 0.11$. However, at stress, this pattern was reversed with endocardial MBF increasing significantly less than epicardial $\operatorname{MBF}(2.00 \pm 0.76 \mathrm{ml} / \mathrm{g} / \mathrm{min}$ versus $2.36 \pm 0.83 \mathrm{ml} / \mathrm{g} / \mathrm{min}$, $\mathrm{P}<0.001)$ giving a ratio of $0.85 \pm 0.18$. The more blunted hyperemic response in the endocardium relative to the epicardium was also reflected by a significantly lower mean MPRI $(1.68 \pm 0.65$ versus $2.06 \pm 0.73, \mathrm{P}<0.001$ respectively).

\section{Perfusion and LV wall thickness}

There was no significant relationship between resting MBF and sector end-diastolic wall thickness. However, at stress, there was a negative correlation between the two $(\beta=-0.047 \mathrm{ml} / \mathrm{g} / \mathrm{min}$ per $\mathrm{mm}, 95 \%$ confidence interval $[C I]:-0.057$ to $-0.038, \mathrm{P}<0.001)$ with similar falls in the endocardium and the epicardium $(\beta=-0.048 \mathrm{ml} / \mathrm{g} / \mathrm{min}$ per $\mathrm{mm}, 95 \% \mathrm{CI}:-0.058$ to $-0.039, \mathrm{P}<0.001$ and $\beta=-0.048 \mathrm{ml} /$ $\mathrm{g} / \mathrm{min}$ per $\mathrm{mm}, 95 \% \mathrm{CI}:-0.058$ to $-0.038, \mathrm{P}<0.001$, respectively).

\section{Perfusion and late gadolinium enhancement}

Segments with LGE were significantly associated with lower perfusion at rest (odds ratio [OR] per $\mathrm{ml} / \mathrm{g} / \mathrm{min}$ increase in MBF: $0.086,95 \% \mathrm{CI}: 0.078$ to $0.095, \mathrm{P}=0.003$ ). This relationship remained consistent at stress (OR: 0.086, 95\% CI: 0.081 to $0.092, \mathrm{P}<0.001)$ and when examined in relation to MPRI (OR: $0.053,95 \%$ CI 0.032 to $0.089, \mathrm{P}=$ $0.015)$. Both rest and stress MBF appeared to be significantly lower in segments with LGE relative to those without (Figure 5A), resulting in a significant difference in MPRI between segments with and without LGE (MPRI: $1.80 \pm 0.74$ versus $1.92 \pm 0.64, \mathrm{P}<0.001$ respectively) 

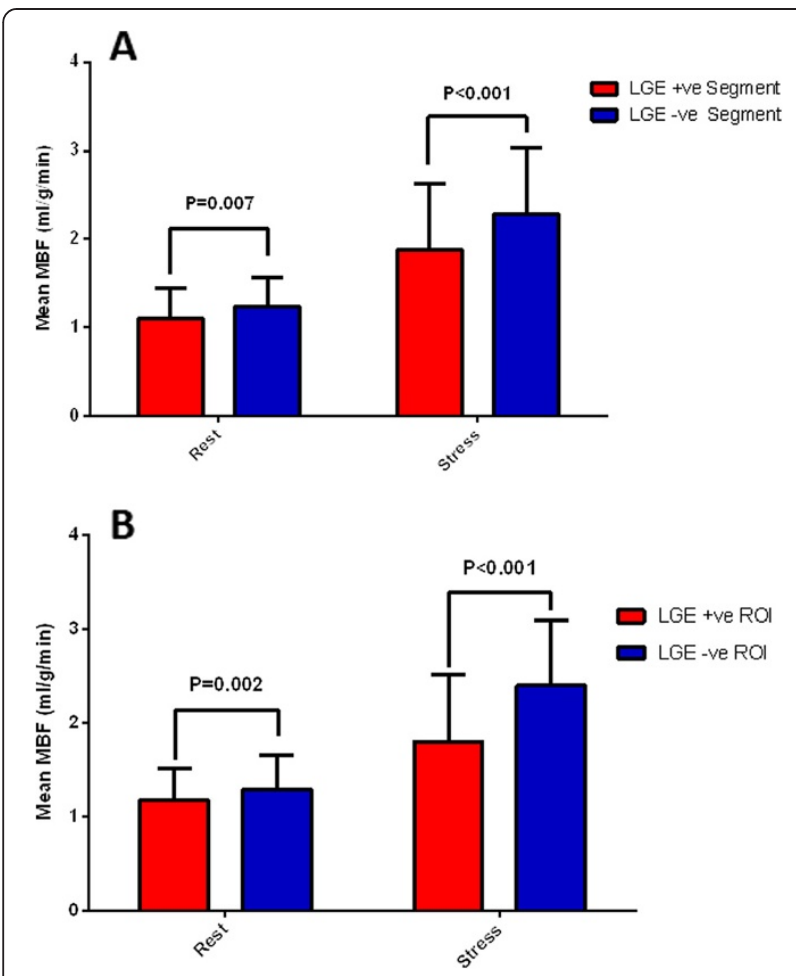

Figure 5 Mean myocardial blood flow (MBF) in (A) segments and $(\mathrm{B})$ regions of interest $(\mathrm{ROI})$ with and without late gadolinium enhancement (LGE).

However, these differences did not persist after adjusting for differences in wall thickness.

ROI analysis on pixel-level perfusion maps revealed a similar, yet stronger trend of reduced MBF when comparing areas of LGE to remote areas free of LGE. This trend was observed for both rest and stress (Figure 5B). As a result, the MPRI was significantly lower in ROI with LGE than in remote areas $(1.61 \pm 0.65$ versus $1.92 \pm 0.54$, $\mathrm{P}<0.001)$.

\section{Discussion}

We found evidence of widespread microvascular dysfunction in a cohort of patients with HCM being studied with multiparametric CMR. To our knowledge, this is the first study to assess stress myocardial perfusion in HCM with CMR using pixel-wise quantification techniques. This allowed us to examine perfusion abnormalities at an unprecedented level of detail. In a subset of patients, pixelwise analysis revealed regions with not only a blunted or inadequate hyperemic response to vasodilator stress, but evidence of severe microvascular dysfunction that is likely to result in ischemia, with stress MBF levels below those of rest perfusion.

In keeping with earlier work, we found that resting endocardial MBF was significantly higher than epicardial MBF [18]. This may reflect the higher systolic wall tension and consequent higher metabolic requirements experienced by the endocardium [34,35]. However, this transmural gradient of perfusion reversed with vasodilator stress to the detriment of the endocardium. The transmural redistribution of perfusion with stress is likely to be due to a combination of the effects of abnormal vascular resistance secondary to arteriolar medial hypertrophy and intimal hyperplasia; higher extravascular compressive forces within the endocardium; and abnormal autoregulation in response to vasodilator stress $[34,36,37]$. In support of this, as in Petersen et al. [18], we noted a significant relationship between wall thickness and perfusion, however, abnormalities in perfusion were also found in areas with normal wall thickness suggesting that abnormalities in vascular structure and vasomotor function may play a pre-eminent role in the genesis of microvascular ischemia in HCM $[18,38,39]$. This is in contrast to the situation with secondary LVH where extravascular factors may play a more predominant role $[15,40]$.

High spatial resolution non-invasive first-pass perfusion CMR techniques therefore provided valuable insights into transmural patterns of MBF, which have hitherto only been possible using microspheres, restricting such work to research in animal models [41].

Layer or sector-based analysis of MBF responses to adenosine in HCM, both in the present study and in previous work, have revealed markedly impaired vasodilator reserve. In contrast to previous work [18], pixel-wise analysis revealed evidence of severe microvascular dysfunction in hypoperfused areas, with MBF at stress actually falling below baseline resting values. This implies that there are regions in which structural abnormalities in the microvasculature and abnormal vasomotion engender vulnerability or lead to frank ischemia.

Severe microvascular dysfunction was identified only in $31 \%$ of patients, potentially identifying a higher risk subgroup of patients at risk of future adverse cardiac events. In a similar cohort of low risk and minimally symptomatic HCM patients, using PET perfusion imaging, Cecchi et al. identified a stress MBF of $1.10 \mathrm{ml} / \mathrm{g} / \mathrm{min}$ as the threshold best predictive of future risk [19]. Intriguingly, the mean stress MBF of patients with severe microvascular dysfunction in the present study was $1.05 \mathrm{ml} / \mathrm{g} / \mathrm{min}$ and the prevalence of severe microvascular dysfunction mirrored the rate of adverse cardiac events observed over long-term clinical follow-up by Cecchi et al. [19].

Myocardial ischemia has been proposed as a progenitor of replacement fibrosis which can be detected by the LGE technique and on histology $[4,6]$. In keeping with the findings of Petersen et al. [18], and work by Sogtia et al. using PET-perfusion imaging in concert with LGE-CMR [22], we found a strong inverse association between the presence of LGE and hyperemic MBF both with ROI and sector-based analyses. In contrast to Petersen et al. but in 
agreement with Knaapen et al. [21], we also found reductions in resting MBF in sectors with LGE. However, neither stress nor rest differences persisted after adjusting for differences in wall thickness. Thus, while there is a strong association between impaired hyperemic MBF and the presence of LGE, this may be confounded by local disease severity as indirectly reflected by local wall thickness. On histology, Varnava et al. found a poor interrelationship between myocardial fibrosis, small vessel disease and disarray [16]. These findings are also in accord with those of Tyan et al. who semi-quantitatively assessed the distribution of perfusion abnormalities and tissue injury using CMR [42]. The absence of a dose-response relationship between reduced hyperemic MBF and the observed spatial distribution of LGE suggests that factors other than or beyond ischemia must be implicated in the pathogenesis of replacement fibrosis in HCM. Although the subendocardium is most severely affected by microvascular ischemia, paradoxically, the overwhelming preponderance of LGE is seen in a mid-wall distribution, typically sparing the sub-endocardium $[14,43]$. This implies that factors beyond microvascular ischemia, possibly under genetic or epigenetic control significantly modulate the development of replacement fibrosis in HCM. Further work is required to delineate the interrelationships of fibrosis and microvascular dysfunction in-vivo, and in particular, their temporal relationship.

\section{Limitations}

The population studied was drawn from referrals to our clinical service which is a tertiary center, leading to potential selection bias towards higher risk cases. However, patients with implantable cardioverter defibrillators (ICDs) who have been deemed high risk will have been excluded due to the contraindication of CMR in this group potentially counterbalancing this. In addition, $97 \%$ of patients had 0 or only 1 risk factor for SCD.

Myocardial fibrosis was assessed using the LGE technique. Whilst this detects replacement fibrosis, it does not allow the quantification of interstitial fibrosis [44]. The association between fibrosis and perfusion abnormalities may therefore have been underappreciated. Nevertheless, replacement fibrosis is thought to be driven by ischemic necrosis and is the distinct type of fibrosis that has been most clearly associated with myocardial ischemia in HCM $[4,5,24]$. Future developments in interstitial imaging using T1-mapping techniques may allow the relationship between interstitial fibrosis, total fibrotic burden and perfusion to be addressed [44].

Finally, we were unable to determine the prognostic significance of our findings given our limited sample size and the relatively low event rate seen in HCM [45]. Nevertheless, our finding of severe microvascular dysfunction in a subgroup of patients with HCM warrants further investigation to determine the potential utility of this phenomenon for risk stratification.

\section{Conclusions}

In summary, coronary microvascular dysfunction is a common finding in HCM and is associated with increasing wall thickness and with the presence of LGE. Fully quantitative pixel-wise first-pass CMR perfusion imaging identifies a significant number of patients with localised severe microvascular dysfunction that is likely to result in ischemia. Further work is required to determine if this phenomenon heralds an increased risk of future adverse cardiovascular events.

\section{Competing interests}

Professor Dudley J Pennell is a consultant to Siemens and a director of Cardiovascular Imaging Solutions. The Royal Brompton Hospital has research collaboration agreements with Siemens.

\section{Authors' contributions}

TFI, LYH, DF, DJP, SKP, and AEA were involved in the conception and design of the study as well as data collection, analysis, interpretation, and drafting of the manuscript. TFI, LYH, AMG, CG, BH, NM, RW, PF, and PG were involved in data gathering, analysis, interpretation, protocol development, drafting and revision of the manuscript. $\mathrm{AJ}, \mathrm{AG}$ and $\mathrm{ROH}$ were involved in data analysis, drafting of the manuscript and in its revision for important content. MR performed all statistical analysis. All authors critically revised the manuscript for important intellectual content, read and approved the final manuscript.

\section{Acknowledgements}

The authors are grateful to the staff of the CMR Unit and the Cardiovascular Biomedical Research Unit, Royal Brompton Hospital, London, UK and the National Institutes of Health, Bethesda, Maryland, USA, for their support with this work. This work was supported by the National Institute of Health Research Cardiovascular Biomedical Research Unit at the Royal Brompton Hospital and Imperial College, London. Dr Ismail and Dr Prasad are funded by the British Heart Foundation. Dr Prasad has also received funding from CORDA, a research charity, and the Rosetrees Trust. Dr Arai and Dr Hsu are funded by the Intramural Research Program of the National Heart, Lung and Blood Institute, National Institutes of Health (Grant \#HL 006137-04).

\section{Author details}

${ }^{1}$ Cardiovascular Magnetic Resonance and Cardiovascular Biomedical Research Units, Royal Brompton Hospital, London, UK. ${ }^{2}$ Imperial College London, London, UK. ${ }^{3}$ Advanced Cardiovascular Imaging Laboratory, National Heart, Lung, and Blood Institute, National Institutes of Health, Bethesda, Maryland, USA. ${ }^{4}$ R-Squared Statistics, London, UK.

Received: 17 November 2013 Accepted: 20 June 2014 Published: 12 August 2014

\section{References}

1. Elliott P, McKenna WJ. Hypertrophic cardiomyopathy. Lancet. 2004; 363:1881-91.

2. Maron BJ. Hypertrophic cardiomyopathy: a systematic review. JAMA. 2002; 287:1308-20.

3. Maron BJ, Gardin JM, Flack JM, Gidding SS, Kurosaki TT, Bild DE. Prevalence of hypertrophic cardiomyopathy in a general population of young adults. Echocardiographic analysis of 4111 subjects in the CARDIA Study. Coronary artery risk development in (Young) Adults. Circulation. 1995; 92:785-9.

4. Basso C, Thiene G, Corrado D, Buja G, Melacini P, Nava A. Hypertrophic cardiomyopathy and sudden death in the young: pathologic evidence of myocardial ischemia. Hum Pathol. 2000; 31:988-98.

5. Maron BJ, Epstein SE, Roberts WC. Hypertrophic cardiomyopathy and transmural myocardial infarction without significant atherosclerosis of the extramural coronary arteries. Am J Cardiol. 1979; 43:1086-102. 
6. Maron MS, Olivotto I, Maron BJ, Prasad SK, Cecchi F, Udelson JE, Camici PG. The case for myocardial ischemia in hypertrophic cardiomyopathy. J Am Coll Cardiol. 2009; 54:866-75.

7. Bruder O, Wagner A, Jensen CJ, Schneider S, Ong P, Kispert EM, Nassenstein K, Schlosser T, Sabin GV, Sechtem U, Mahrholdt H. Myocardial scar visualized by cardiovascular magnetic resonance imaging predicts major adverse events in patients with hypertrophic cardiomyopathy. J Am Coll Cardiol. 2010; 56:875-87.

8. Green JJ, Berger JS, Kramer CM, Salerno M. Prognostic value of late gadolinium enhancement in clinical outcomes for hypertrophic cardiomyopathy. JACC Cardiovasc Imaging. 2012; 5:370-7.

9. Ismail TF, Prasad SK, Pennell DJ. Prognostic importance of late gadolinium enhancement cardiovascular magnetic resonance in cardiomyopathy. Heart. 2012: 98:438-42.

10. Maron MS, Appelbaum E, Harrigan CJ, Buros J, Gibson CM, Hanna C, Lesser JR, Udelson JE, Manning WJ, Maron BJ. Clinical profile and significance of delayed enhancement in hypertrophic cardiomyopathy. Circ Heart Fail. 2008; 1:184-91.

11. Moon JC, McKenna WJ, McCrohon JA, Elliott PM, Smith GC, Pennell DJ. Toward clinical risk assessment in hypertrophic cardiomyopathy with gadolinium cardiovascular magnetic resonance. J Am Coll Cardiol. 2003; 41:1561-7.

12. O'Hanlon R, Grasso A, Roughton M, Moon JC, Clark S, Wage R, Webb J, Kulkarni M, Dawson D, Sulaibeekh L, Chandrasekaran B, Bucciarelli-Ducci C, Pasquale F, Cowie MR, McKenna WJ, Sheppard MN, Elliott PM, Pennell DJ, Prasad SK. Prognostic significance of myocardial fibrosis in hypertrophic cardiomyopathy. J Am Coll Cardiol. 2010; 56:867-74.

13. Rubinshtein R, Glockner JF, Ommen SR, Araoz PA, Ackerman MJ, Sorajja P, Bos JM, Tajik AJ, Valeti US, Nishimura RA, Gersh BJ. Characteristics and clinical significance of late gadolinium enhancement by contrastenhanced magnetic resonance imaging in patients with hypertrophic cardiomyopathy. Circ Heart Fail. 2010; 3:51-8.

14. Mahrholdt H, Wagner A, Judd RM, Sechtem U, Kim RJ. Delayed enhancement cardiovascular magnetic resonance assessment of non-ischaemic cardiomyopathies. Eur Heart J. 2005; 26:1461-74.

15. Camici PG, Olivotto I, Rimoldi OE. The coronary circulation and blood flow in left ventricular hypertrophy. J Mol Cell Cardiol. 2012; 52:857-64.

16. Varnava AM, Elliott PM, Sharma S, McKenna WJ, Davies MJ. Hypertrophic cardiomyopathy: the interrelation of disarray, fibrosis, and small vessel disease. Heart. 2000; 84:476-82

17. Pennell DJ. Cardiovascular magnetic resonance. Circulation. 2010; 121:692-705.

18. Petersen SE, Jerosch-Herold M, Hudsmith LE, Robson MD, Francis JM, Doll HA Selvanayagam JB, Neubauer S, Watkins H. Evidence for microvascular dysfunction in hypertrophic cardiomyopathy: new insights from multiparametric magnetic resonance imaging. Circulation. 2007; 115:2418-25.

19. Cecchi F, Olivotto I, Gistri R, Lorenzoni R, Chiriatti G, Camici PG. Coronary microvascular dysfunction and prognosis in hypertrophic cardiomyopathy. N Engl J Med. 2003; 349:1027-35

20. Choudhury L, Rosen SD, Patel D, Nihoyannopoulos P, Camici PG. Coronary vasodilator reserve in primary and secondary left ventricular hypertrophy. A study with positron emission tomography. Eur Heart J. 1997; 18:108-16.

21. Knaapen P, van Dockum WG, Gotte MJ, Broeze KA, Kuijer JP, Zwanenburg J, Marcus JT, Kok WE, van Rossum AC, Lammertsma AA, Visser FC. Regional heterogeneity of resting perfusion in hypertrophic cardiomyopathy is related to delayed contrast enhancement but not to systolic function: a PET and MRI study. J NuCl Cardiol. 2006; 13:660-7.

22. Sotgia B, Sciagra R, Olivotto I, Casolo G, Rega L, Betti I, Pupi A, Camici PG, Cecchi F. Spatial relationship between coronary microvascular dysfunction and delayed contrast enhancement in patients with hypertrophic cardiomyopathy. J NuCl Med. 2008; 49:1090-6.

23. Hsu LY, Groves DW, Aletras AH, Kellman P, Arai AE. A quantitative pixel-wise measurement of myocardial blood flow by contrast-enhanced first-pass CMR perfusion imaging: microsphere validation in dogs and feasibility study in humans. JACC Cardiovasc Imaging. 2012; 5:154-66.

24. Kwon DH, Smedira NG, Rodriguez ER, Tan C, Setser R, Thamilarasan M, Lytle BW, Lever HM, Desai MY. Cardiac magnetic resonance detection of myocardial scarring in hypertrophic cardiomyopathy: correlation with histopathology and prevalence of ventricular tachycardia. J Am Coll Cardiol. 2009; 54:242-9.
25. Gersh BJ, Maron BJ, Bonow RO, Dearani JA, Fifer MA, Link MS, Naidu SS, Nishimura RA, Ommen SR, Rakowski H, Seidman CE, Towbin JA, Udelson JE, Yancy CW. 2011 ACCF/AHA Guideline for the Diagnosis and Treatment of Hypertrophic Cardiomyopathy: a report of the American College of Cardiology Foundation/American Heart Association Task Force on Practice Guidelines. Developed in collaboration with the American Association for Thoracic Surgery, American Society of Echocardiography, American Society of Nuclear Cardiology, Heart Failure Society of America, Heart Rhythm Society, Society for Cardiovascular Angiography and Interventions, and Society of Thoracic Surgeons. J Am Coll Cardiol. 2011; 58:e212-60

26. Kramer CM, Barkhausen J, Flamm SD, Kim RJ, Nagel E. Standardized cardiovascular magnetic resonance imaging (CMR) protocols, society for cardiovascular magnetic resonance: board of trustees task force on standardized protocols. J Cardiovasc Magn Reson. 2008; 10:35.

27. Ding S, Wolff SD, Epstein FH. Improved coverage in dynamic contrastenhanced cardiac MRI using interleaved gradient-echo EPI. Magn Reson Med. 1998; 39:514-9.

28. Kim D, Cernicanu A, Axel L. B(0) and B(1)-insensitive uniform T(1)weighting for quantitative, first-pass myocardial perfusion magnetic resonance imaging. Magn Reson Med. 2005; 54:1423-9.

29. Ferreira PF, Gatehouse PD, Firmin DN. Myocardial first-pass perfusion imaging with hybrid-EPI: frequency-offsets and potential artefacts. J Cardiovasc Magn Reson. 2012; 14:44

30. Gatehouse PD, Elkington AG, Ablitt NA, Yang GZ, Pennell DJ, Firmin DN. Accurate assessment of the arterial input function during high-dose myocardial perfusion cardiovascular magnetic resonance. J Magn Reson Imaging. 2004; 20:39-45.

31. Simonetti OP, Kim RJ, Fieno DS, Hillenbrand HB, Wu E, Bundy JM, Finn JP, Judd RM. An improved MR imaging technique for the visualization of myocardial infarction. Radiology. 2001; 218:215-23.

32. Maceira AM, Prasad SK, Khan M, Pennell DJ. Normalized left ventricular systolic and diastolic function by steady state free precession cardiovascular magnetic resonance. J Cardiovasc Magn Reson. 2006; 8:417-26.

33. Cerqueira MD, Weissman NJ, Dilsizian V, Jacobs AK, Kaul S, Laskey WK Pennell DJ, Rumberger JA, Ryan T, Verani MS. Standardized myocardial segmentation and nomenclature for tomographic imaging of the heart: a statement for healthcare professionals from the Cardiac Imaging Committee of the Council on Clinical Cardiology of the American Heart Association. Circulation. 2002; 105:539-42.

34. Weiss HR. Regional oxygen consumption and supply in the rabbit heart effect of nitroglycerin and propranolol. J Pharmacol Exp Ther. 1979; 211:68-73.

35. Weiss HR. Regional oxygen consumption and supply in the dog heart: effect of atrial pacing. Am J Physiol. 1979; 236:H231-7.

36. Mundhenke M, Schwartzkopff B, Strauer BE. Structural analysis of arteriolar and myocardial remodelling in the subendocardial region of patients with hypertensive heart disease and hypertrophic cardiomyopathy. Virchows Archiv. 1997; 431:265-73.

37. Schwartzkopff B, Mundhenke M, Strauer BE. Alterations of the architecture of subendocardial arterioles in patients with hypertrophic cardiomyopathy and impaired coronary vasodilator reserve: a possible cause for myocardial ischemia. J Am Coll Cardiol. 1998; 31:1089-96.

38. Krams R, Kofflard MJ, Duncker DJ, Von Birgelen C, Carlier S, Kliffen M, ten Cate FJ, Serruys PW. Decreased coronary flow reserve in hypertrophic cardiomyopathy is related to remodeling of the coronary microcirculation. Circulation. 1998; 97:230-3.

39. Camici P, Chiriatti G, Lorenzoni R, Bellina RC, Gistri R, Italiani G, Parodi O, Salvadori PA, Nista N, Papi L, L'Abbate A. Coronary vasodilation is impaired in both hypertrophied and nonhypertrophied myocardium of patients with hypertrophic cardiomyopathy: a study with nitrogen-13 ammonia and positron emission tomography. J Am Coll Cardiol. 1991; 17:879-86.

40. Duncker DJ, Ishibashi Y, Bache RJ. Effect of treadmill exercise on transmural distribution of blood flow in hypertrophied left ventricle. Am J Physiol. 1998; 275:H1274-82.

41. Utley J, Carlson EL, Hoffman JI, Martinez HM, Buckberg GD. Total and regional myocardial blood flow measurements with 25 micron, 15 micron, 9 micron, and filtered 1-10 micron diameter microspheres and antipyrine in dogs and sheep. Circ Res. 1974; 34:391-405.

42. Tyan CC, Armstrong S, Scholl D, Stirrat J, Blackwood K, El-Sherif O, Thompson T, Wisenberg G, Prato FS, So A, Lee TY, Drangova M, White JA. Stress 
hypoperfusion and tissue injury in hypertrophic cardiomyopathy: spatial characterization using high-resolution 3-tesla magnetic resonance imaging. Circ Cardiovasc Imaging. 2013; 6:229-38

43. Noureldin RA, Liu S, Nacif MS, Judge DP, Halushka MK, Abraham TP, Ho C, Bluemke DA. The diagnosis of hypertrophic cardiomyopathy by cardiovascular magnetic resonance. J Cardiovasc Magn Reson. 2012; 14:17.

44. Mewton N, Liu CY, Croisille P, Bluemke D, Lima JA. Assessment of myocardial fibrosis with cardiovascular magnetic resonance. J Am Coll Cardiol. 2011; 57:891-903.

45. Cecchi F, Olivotto I, Montereggi A, Santoro G, Dolara A, Maron BJ. Hypertrophic cardiomyopathy in Tuscany: clinical course and outcome in an unselected regional population. J Am Coll Cardiol. 1995; 26:1529-36.

doi:10.1186/s12968-014-0049-1

Cite this article as: Ismail et al: Coronary microvascular ischemia in hypertrophic cardiomyopathy - a pixel-wise quantitative cardiovascular magnetic resonance perfusion study. Journal of Cardiovascular Magnetic Resonance 2014 16:49.

\section{Submit your next manuscript to BioMed Central and take full advantage of:}

- Convenient online submission

- Thorough peer review

- No space constraints or color figure charges

- Immediate publication on acceptance

- Inclusion in PubMed, CAS, Scopus and Google Scholar

- Research which is freely available for redistribution 